\title{
The Amine Group as Halogen Bond Acceptor in Cocrystals of Aromatic Diamines and Perfluorinated Iodobenzenes
}

\author{
Erik Uran, Luka Fotović, Nikola Bedeković (D), Vladimir Stilinović *(D) and Dominik Cinčić *(D)
}

check for updates

Citation: Uran, E.; Fotović, L.;

Bedeković, N.; Stilinović, V.; Cinčić, D.

The Amine Group as Halogen Bond Acceptor in Cocrystals of Aromatic

Diamines and Perfluorinated

Iodobenzenes. Crystals 2021, 11, 529.

https://doi.org/10.3390/cryst11050529

Academic Editor: Sergiy Rosokha

Received: 19 April 2021

Accepted: 27 April 2021

Published: 11 May 2021

Publisher's Note: MDPI stays neutral with regard to jurisdictional claims in published maps and institutional affiliations.

Copyright: (c) 2021 by the authors. Licensee MDPI, Basel, Switzerland. This article is an open access article distributed under the terms and conditions of the Creative Commons Attribution (CC BY) license (https:/ / creativecommons.org/licenses/by/ $4.0 /)$.
Department of Chemistry, Faculty of Science, University of Zagreb, Horvatovac 102a, HR-10002 Zagreb, Croatia; euran@chem.pmf.hr (E.U.); lfotovic@chem.pmf.hr (L.F.); nbedekovic@chem.pmf.hr (N.B.)

* Correspondence: vstilinovic@chem.pmf.hr (V.S.); dominik@chem.pmf.hr (D.C.); Tel.: +385-1-4606-371 (V.S.); $+385-1-4606-362$ (D.C.)

\begin{abstract}
In order to study the proclivity of primary amine groups to act as halogen bond acceptors, three aromatic diamines ( $p$-phenylenediamine (pphda), benzidine (bnzd) and $o$-tolidine (otol)) were cocrystallised with three perfluorinated iodobenzenes (1,4-tetrafluorodiiodobenzene (14tfib), 1,3tetrafluorodiiodobenzene (13tfib) and 1,3,5-trifluorotriiodobenzene (135tfib)) as halogen bond donors. Five cocrystals were obtained: (pphda)(14tfib), (bnzd)(13tfib) $)_{2},(\text { bnzd)(135tfib) })_{4},($ otol)(14tfib) and (otol)(135tfib) $)_{2}$. In spite of the variability of both stoichiometries and structures of the cocrystals, in all the prepared cocrystals the amine groups form exclusively $\mathrm{I} \cdots \mathrm{N}$ halogen bonds, while the amine hydrogen atoms participate mostly in $\mathrm{N}-\mathrm{H} \cdots \mathrm{F}$ contacts. The preference of the amine nitrogen atom toward the halogen bond, as opposed to the hydrogen bond (with amine as a donor), is rationalised by means of computed hydrogen and halogen bond energies, indicating that the halogen bond energy between a simple primary amine (methylamine) and a perfluorinated iodobenzene (pentafluoroiodobenze ne) is ca. $15 \mathrm{~kJ} \mathrm{~mol}^{-1}$ higher than the energy of the $(\mathrm{H}) \mathrm{NH} \cdots \mathrm{NH}_{2}$ hydrogen bond between two amine molecules.
\end{abstract}

Keywords: halogen bonding; aromatic diamines; perfluorinated iodobenzenes; amine group

\section{Introduction}

From the beginning of the intensive research into halogen bonding at the turn of the millennium [1-5], one of the main areas of interest (apart from the fundamental studies of the nature and properties of the halogen bond) has been to utilize the halogen bond as a reliable non-covalent molecular interaction in supramolecular chemistry in general [6-9], and particularly in crystal engineering [10-14], as a means of the deliberate design of multi-component organic [15,16] and metal-organic [17-20] materials, both comprising ionic species (salts) [21-26] and neutral molecules (cocrystals) [27-36].

The most commonly employed neutral halogen bond donors in crystal engineering to date have been perfluorinated iodobenzenes, namely, 1,2-tetrafluorodiiodobenzene (12tfib), 1,4-tetrafluorodiiodobenzene (14tfib), 1,3-tetrafluorodiiodobenzene (13tfib) and 1,3,5-trifluorotriiodobenzene (135tfib) [37-42]. These substances are stable in ambient conditions, soluble in most organic solvents, easy to handle and commercially available. The presence of the electron-withdrawing fluorine atoms in the molecule increases the positive electrostatic potential of the $\sigma$-holes of the iodine atoms, making them reliable halogen bond donors for a wide range of organic and metal-organic Lewis bases [43,44]. However, their reliability as halogen bond donors can be severely reduced by the formation of competing hydrogen bonds. The balance between halogen and hydrogen bonds in systems where the two can compete is often quite delicate, and can be influenced by various factors, such as weak interactions and overall crystal packing $[45,46]$, the choice of crystallisation solvent [47] and even the amount of solvent used in the cocrystal synthesis [48]. For these reasons, the result of a supramolecular synthesis in systems where there is competition 
between halogen and hydrogen donors for the (same) acceptor sites generally cannot be unequivocally predicted.

A typical acceptor group where the reliability of halogen bond fails is the primary amine group $\left(-\mathrm{NH}_{2}\right)$. Normally, the nitrogen atom is one of the most reliable bases for the formation of halogen bonds in general, and with perfluorinated iodobenzenes in particular. According to the data deposited with the Cambridge Structural Database (CSD) [49], there have been 686 crystal structures containing a perfluorinated iodobenzene and a nitrogen atom reported to date; of these, $430(63 \%)$ feature the $\mathrm{C}-\mathrm{I} \cdots \mathrm{N}$ halogen bond. However, out of the (only) 50 structures containing perfluorinated iodobenzene and a primary amine group, only in 5 of them (a mere $10 \%$ ) is a $\mathrm{C}-\mathrm{I} \cdots \mathrm{N}$ (amino) halogen bond present. It is tempting to attribute this to the ability of the primary amine nitrogen to also act as both a hydrogen bond donor and an acceptor. However, the amine group is a rather poor hydrogen bond donor-the $\mathrm{R}-\mathrm{N}(\mathrm{H})-\mathrm{H} \cdots \mathrm{NH}_{2}$ hydrogen bond can be found to be present in only about $5 \%$ of all the structures containing (either aromatic or aliphatic) a primary amine group (1965 out of 42,021), while generally in the presence of $\mathrm{NH}$ or OH hydrogen bond donors it acts as a hydrogen bond acceptor in about $13 \%$ of cases $(4434$ out of 33,964$)$. Therefore, the more probable reason for the low occurrence of halogen bonds involving the primary amine group is the presence of better halogen bond acceptor sites in the molecule (such as heterocyclic aromatic nitrogen atoms). This conclusion is also borne out by an earlier study of aromatic amines as halogen bond acceptors performed within our group [50], which has demonstrated that the primary amine group acted as a halogen bond acceptor only if no stronger halogen bond acceptors (such as heterocyclic nitrogen, carboxylic and even nitro groups) were present.

In this work, we endeavoured to study the halogen bonding proclivity of the aromatic primary amino group in the absence of other electronegative atoms or functional groups which might compete with the primary amine nitrogen as halogen bond acceptors. For this purpose, we selected three aromatic primary diamines ( $p$-phenylenediamine (benzene-1,4-diamine, pphda), benzidine (1,1'-biphenyl-4,4'-diamine, bnzd) and $o$-tolidine (3,3'-dimethyl-[1,1'-biphenyl]-4,4'-diamine, otol); Scheme 1) as (potential) halogen bond acceptors. The crystal structures of all three have been previously reported [51-53], demonstrating that almost every nitrogen atom in each of the structures of the pure diamines does act as a hydrogen bond acceptor (the exception being two out of the four polymorphs in bnzd-each with multiple molecules of bnzd in the asymmetric unit-where some of the $\mathrm{NH}_{2}$ nitrogen atoms do not). This makes them an excellent platform for a study of the competition of $-\mathrm{R}-\mathrm{N}(\mathrm{H})-\mathrm{H} \cdots \mathrm{NH}_{2}$ hydrogen bonds and $\mathrm{C}-\mathrm{I} \cdots \mathrm{NH}_{2}$ halogen bonds. The competition was studied by attempting to cocrystallise each of the three selected diamines with three selected perfluorinated iodobenzenes (14tfib, 13tfib and 135tfib) as halogen bond donors (Scheme 1). The cocrystallisation screening was performed mechanochemically by liquid-assisted grinding (LAG) in order to determine in how many instances the cocrystals would be formed. The cocrystallisation experiments were also performed from solution in order to produce single crystals of halogen-bonded cocrystals, to be studied by single-crystal X-ray diffraction in order to determine which intermolecular interactions govern their assembly. 

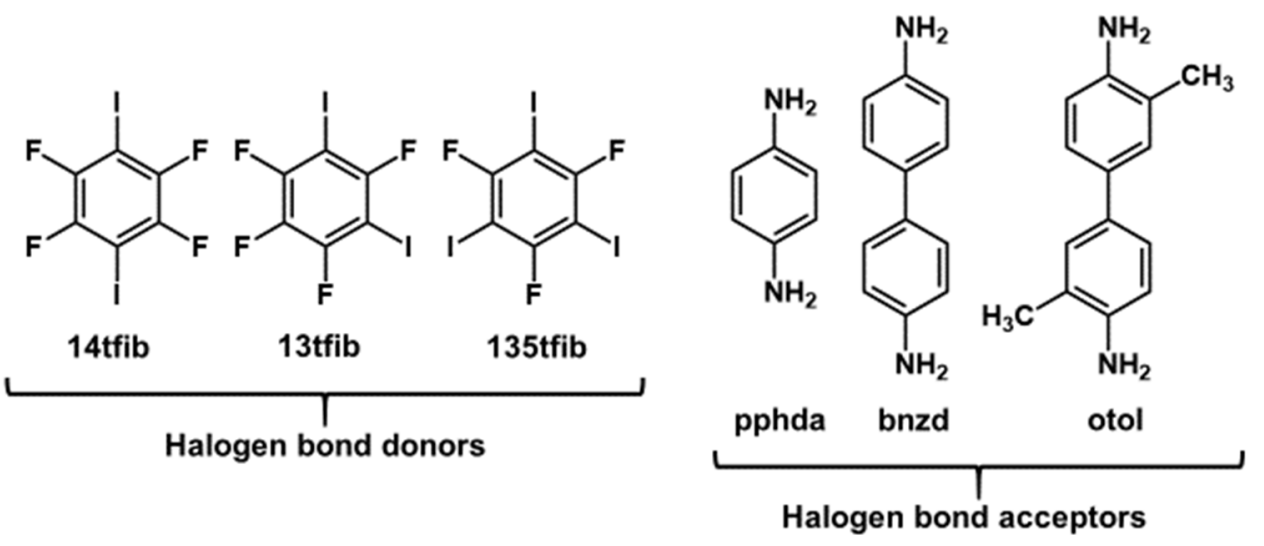

Scheme 1. Halogen bond donors and acceptors used in this study.

\section{Materials and Methods}

All the solvents used (ethanol, acetone, acetonitrile) were procured from SigmaAldrich Chemie GmbH, Taufkirchen, Germany. Benzidine (Sigma-Aldrich Chemie GmbH (Merck Reagents), Taufkirchen, Germany), p-phenylendiamine (Fisher Scientific UK Ltd., Leicestershire, UK) and $o$-tolidine (Kemika, Zagreb, Croatia) were purified by recrystallization from water, while 14tfib (Manchester Organics Ltd., Cheshire, UK), 13tfib (Apollo Scientific Ltd., Cheshire, UK) and 135tfib (Apollo Scientific Ltd., Cheshire, UK), as well as the organic solvents, were used without additional purification.

\subsection{Solution and Single-Crystal Synthesis of Cocrystals}

The corresponding halogen bond donor and diamine were dissolved in $5.0 \mathrm{~mL}$ of a solvent (ethanol or ethanol/acetone mixture), whereupon the solutions were left to cool and slowly evaporate (experimental details are given in the Supplementary Materials, Table S1). The obtained products were characterized by powder X-ray diffraction (PXRD) in order to examine their phase purity. Single crystals suitable for single-crystal X-ray diffraction (SCXRD) experiments were prepared by crystallization from ethanol and appeared after three to seven days. ORTEP plots of the obtained compounds are shown in Figures S1-S5 in the Supplementary Materials.

\subsection{Powder X-ray Diffraction Measurements}

Powder X-ray diffraction experiments on the samples were performed on an Aeris X-ray diffractometer (Malvern Panalytical, Malvern Worcestershire, UK) with CuK $\alpha 1(\lambda=$ $1.54056 \AA$ ) radiation. The scattered intensities were measured with a PIXcel-1D-Medipix3 detector. The angular range was from $5^{\circ}$ to $40^{\circ}(2 \theta)$ with a continuous step size of $0.02^{\circ}$ and measuring a time of $0.5 \mathrm{~s}$ per step.

Data collection methods were created using the program package START XRDMP CREATOR (Malvern Panalytical, Malvern Worcestershire, UK) while the data were analysed using X'Pert HighScore Plus (Version 2.2, Malvern Panalytical, Malvern Worcestershire, UK) [54]. The comparison of measured and calculated PXRD patterns of the prepared compounds are shown in Figures S6-S10 in the Supplementary Materials.

\subsection{Single-Crystal X-ray Diffraction Measurements}

Single-crystal X-ray diffraction experiments were performed using an Oxford Diffraction Xcalibur Kappa CCD X-ray diffractometer (Oxford Diffraction Ltd., Abingdon, UK) with graphite-monochromated $\operatorname{MoK} \alpha(\lambda=0.71073 \AA)$ radiation. The data sets were collected using the $\omega$-scan mode over the $2 \theta$-Range up to $54^{\circ}$. The programs CrysAlis PRO CCD and CrysAlis PRO RED were employed for data collection, cell refinement and data reduction $[55,56]$. The structures were solved and refined using SHELXS (Version 2013, Göttingen, Germany), SHELXL programs (Version 2013, Göttingen, Germany) and SHELXT programs (Version 2013, Göttingen, Germany) respectively [57-59]. The struc- 
tural refinement was performed on $F^{2}$ using all data. The hydrogen atoms were placed in calculated positions and treated as riding on their parent atoms $[\mathrm{C}-\mathrm{H}=0.93 \AA$ and $U_{\text {iso }}(\mathrm{H})=1.2 U_{\text {eq }}(\mathrm{C})$ for aromatic hydrogen atoms; $\mathrm{C}-\mathrm{H}=0.97 \AA$ and $U_{\text {iso }}(\mathrm{H})=1.2 U_{\text {eq }}(\mathrm{C})$ for methyl hydrogen atoms]. The amino group hydrogen atoms were located from the electron difference map and then refined with the following restraints, where necessary: $d(\mathrm{~N}-\mathrm{H})=0.920 \AA, d(\mathrm{H} \cdots \mathrm{H})=1.500 \AA, U_{\mathrm{iso}}(\mathrm{H})=1.5 U_{\mathrm{eq}}(\mathrm{N})$. All calculations were performed using the WinGX crystallographic suite of programs [60]. The figures were prepared using Mercury 2020.2.0 (CCDC, Cambridge, UK) [61]. Crystallographic data of the prepared compounds are shown in Table S2 in the Supplementary Materials.

\subsection{Thermal Analysis}

Differential scanning calorimetry (DSC) and thermogravimetric (TG) measurements were performed simultaneously on a Mettler-Toledo TGA/DSC 3+ module (Mettler Toledo, Greifensee, Switzerland). Samples were placed in alumina crucibles $(40 \mu \mathrm{L})$ and heated in the temperature range 25 to $300{ }^{\circ} \mathrm{C}$, at a heating rate of $10^{\circ} \mathrm{C} \mathrm{min}-1$ under a nitrogen flow of $150 \mathrm{~mL} \mathrm{~min}{ }^{-1}$.

Data collection and analysis were performed using the program package STARe Software (Version 15.00, Mettler Toledo, Greifensee, Switzerland) [62]. TG and DSC curves of the prepared compounds are shown in Figures S11-S15 in the Supplementary Materials.

\subsection{Calculations}

All calculations were performed using the Gaussian 09 (Revision D.01) software package [63]. Geometry optimizations were performed using the B3LYP/def2-TZVP [64-66] level of theory with the D3 version of Grimme's dispersion [67] and an ultrafine integration grid (99 radial shells and 590 points per shell). This method was shown to reproduce experimental halogen bond lengths, complexation energies and vibrational frequencies in the gas phase with good accuracy [68]. The harmonic frequency calculations were performed on the optimized geometries to ensure that they correspond to minima on the potential energy surface.

\section{Results and Discussion}

The crystallisation from solution of the selected diamines and the halogen bond donors yielded five cocrystals, whereas in four cases only the starting materials were isolated. An overview of the obtained cocrystals is given in Table 1.

Table 1. An overview of the obtained cocrystals of aromatic diamines and perfluorinated iodobenzenes.

\begin{tabular}{cccc}
\hline & pphda & bnzd & otol \\
\hline 14tfib & $($ pphda $)($ 14tfib $)$ & - & $($ otol $)(14$ tfib $)$ \\
13tfib & - & $($ bnzd $)(\text { 13tfib })_{2}$ & - \\
135tfib & - & $($ bnzd $)(135 t f i b)_{4}$ & $($ otol $)(135 \text { tfib })_{2}$, \\
\hline
\end{tabular}

$p$-Phenylenediamine was found to form only one cocrystal, (pphda)(14tfib). In the structure of the cocrystal, each diamine molecule is connected to two neighbouring 14tfib molecules by a pair of $\mathrm{I} \cdots \mathrm{NH}_{2}$ halogen bonds $\left(d(\mathrm{I} 1 \cdots \mathrm{N} 1)=2.958(6) \AA, \angle(\mathrm{C} 4-\mathrm{I} 1 \cdots \mathrm{N} 1)=179.0(2)^{\circ}\right)$ so that both amine nitrogen atoms act as halogen bond acceptors. This leads to the formation of halogen bonded chains (Figure 1) in which the amine hydrogen atoms remain free to form hydrogen bonds with fluorine atoms of the 14tfib molecules from neighbouring chains, thus interconnecting the chains through $\mathrm{N}-\mathrm{H} \cdots \mathrm{F}$ contacts $(d(\mathrm{~N} 1 \cdots \mathrm{F} 2)=3.375(6) \AA)$ into layers (Figure 1). 


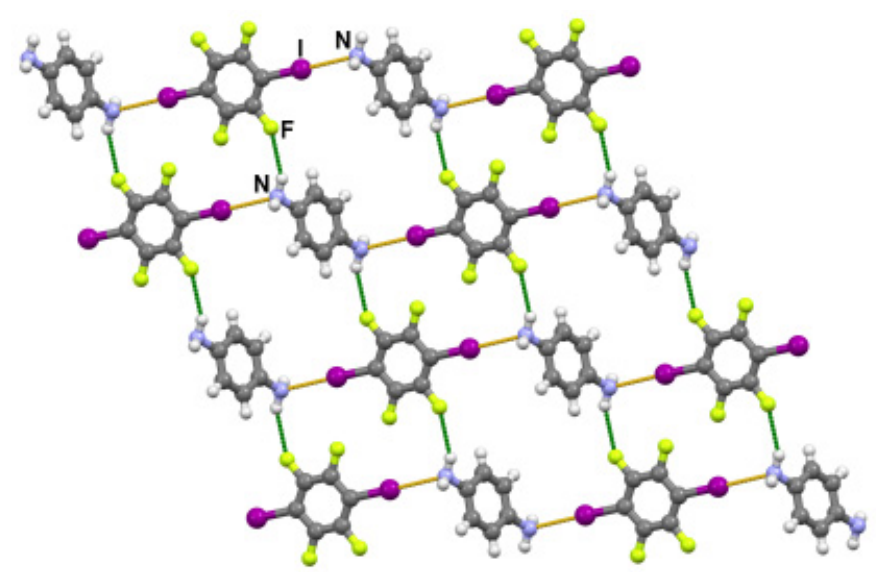

Figure 1. In the structure of (pphda)(14tfib), layers are formed by the linking of halogen bonded (yellow) chains through $\mathrm{N}-\mathrm{H} \cdots \mathrm{F}$ hydrogen bonds (green) in the structure of (pphda)(14tfib).

$o$-Tolidine was found to form two cocrystals: (otol)(14tfib) and (otol)(135tfib) ${ }_{2}$. The halogen bonding in the crystal structure of the former is analogous to that in (pphda)(14tfib) -each diamine is connected to the neighbouring donor molecules by a pair of $\mathrm{I} \cdots \mathrm{NH}_{2}$ halogen bonds, although these are somewhat longer than in (pphda) $(\mathbf{1 4 t f i b})(d(\mathrm{I} 1 \cdots \mathrm{N} 1)=2.977(4) \AA$, $\left.\angle(\mathrm{C} 8-\mathrm{I} 1 \cdots \mathrm{N} 1)=176.8(1)^{\circ}\right)($ Figure 2$)$. The amine hydrogen atoms here also interact with fluorine atoms from the surrounding 14tfib molecules, through a series of bifurcated $\mathrm{N}$ $\mathrm{H} \cdots \mathrm{F}$ contacts $(d(\mathrm{~N} 1 \cdots \mathrm{F} 1)=3.334(5) \AA, d(\mathrm{~N} 1 \cdots \mathrm{F} 2)=3.273(4) \AA)$, again interconnecting the halogen-bonded chains into layers (Figure 2). Additionally, the otol methyl groups participate in $\mathrm{C}-\mathrm{H} \cdots \pi$ contacts $(d(\mathrm{C} 7 \cdots \mathrm{C} 4)=3.607(6) \AA)$ which interconnect the layers into a 3D structure.

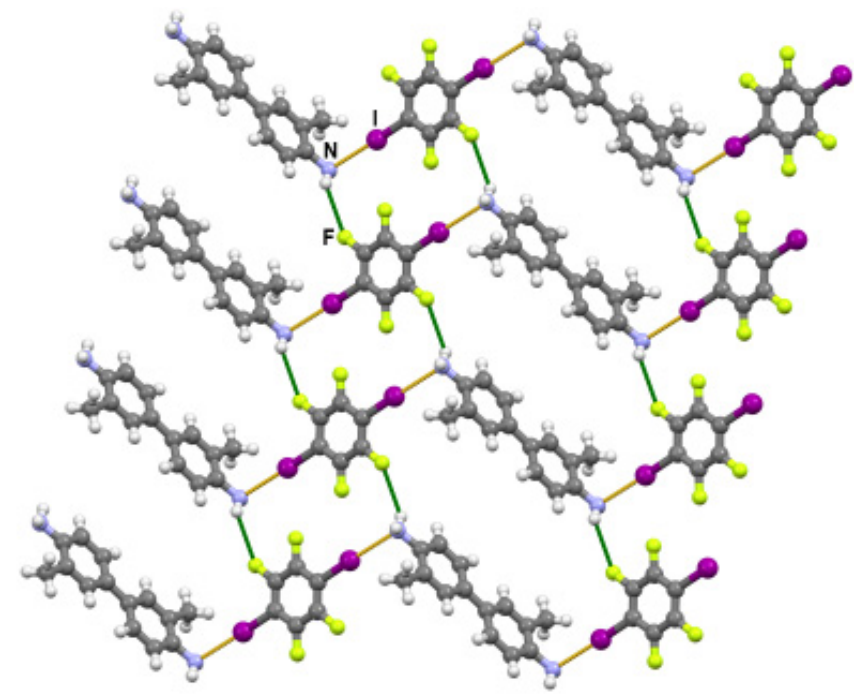

Figure 2. In the structure of (otol)(14tfib), layers are formed by the linking of halogen-bonded (yellow) chains through $\mathrm{N}-\mathrm{H} \cdots \mathrm{F}$ hydrogen bonds (green) in the structure of (otol)(14tfib).

Unlike pphda, otol also formed a cocrystal with the tritopic halogen bond donor, 135tfib. Unlike the cocrystals with 14tfib which were of the expected 1:1 stoichiometry (resulting from a ditopic donor binding with a ditopic acceptor), this was found to present a somewhat unexpected 1:2 stoichiometry with the formula (otol)(135tfib $)_{2}$, significantly deviating from the 3:2 stoichiometry which might be expected based on the respective topicities of the acceptor and the donor. In the crystal structure of (otol)(135tfib) $)_{2}$ cocrystal, again both otol amino groups participate in $\mathrm{I} \cdots \mathrm{NH}_{2}$ halogen bonds $(d(\mathrm{I} 1 \cdots \mathrm{N} 1)=3.035(8) \AA$, $\left.\angle(\mathrm{C} 7-\mathrm{I} 1 \cdots \mathrm{N} 1)=176.9(2)^{\circ}\right)$. Besides this main supramolecular interaction, both the $\pi$ systems of the aromatic diamine act as halogen bond acceptors, forming $\mathrm{I} \cdots \mathrm{C}_{\pi}$ halogen 
bonds [69] with 135tfib molecules $\left(d(\mathrm{I} 3 \cdots \mathrm{C} 5)=3.423(5) \AA, \angle\left(\mathrm{C} 11-\mathrm{I} 3 \cdots \mathrm{C} 5=166.9(2)^{\circ}\right)\right.$ (Figure 3a). Each 135tfib molecule bridges between two molecules of otol, binding to the amino group of one and to the aromatic $\pi$-system of the other. Each otol molecule binds to four 135tfib molecules, two via the amine groups and two via the aromatic rings, thus forming halogen-bonded layers of 1:2 stoichiometry, comprising 8-molecular rings (comprising four otol and four 135tfib molecules, with each otol molecule belonging to four rings and each 135tfib molecule to two; Figure $3 b$ ). The third 135tfib iodine atom does not bind to otol, but rather forms type II halogen $\cdots$ halogen contacts $(d(\mathrm{I} 2 \cdots \mathrm{I} 1)=3.817(1) \AA$, $\left.\angle(C 9-I 2 \cdots \mathrm{I} 1)=163.4(1)^{\circ}\right)$, with the iodine atom participating in an $\mathrm{I} \cdots \mathrm{NH}_{2}$ interaction in a neighbouring layer, thus leading to a 3D halogen-bonded structure (Figure 3c).
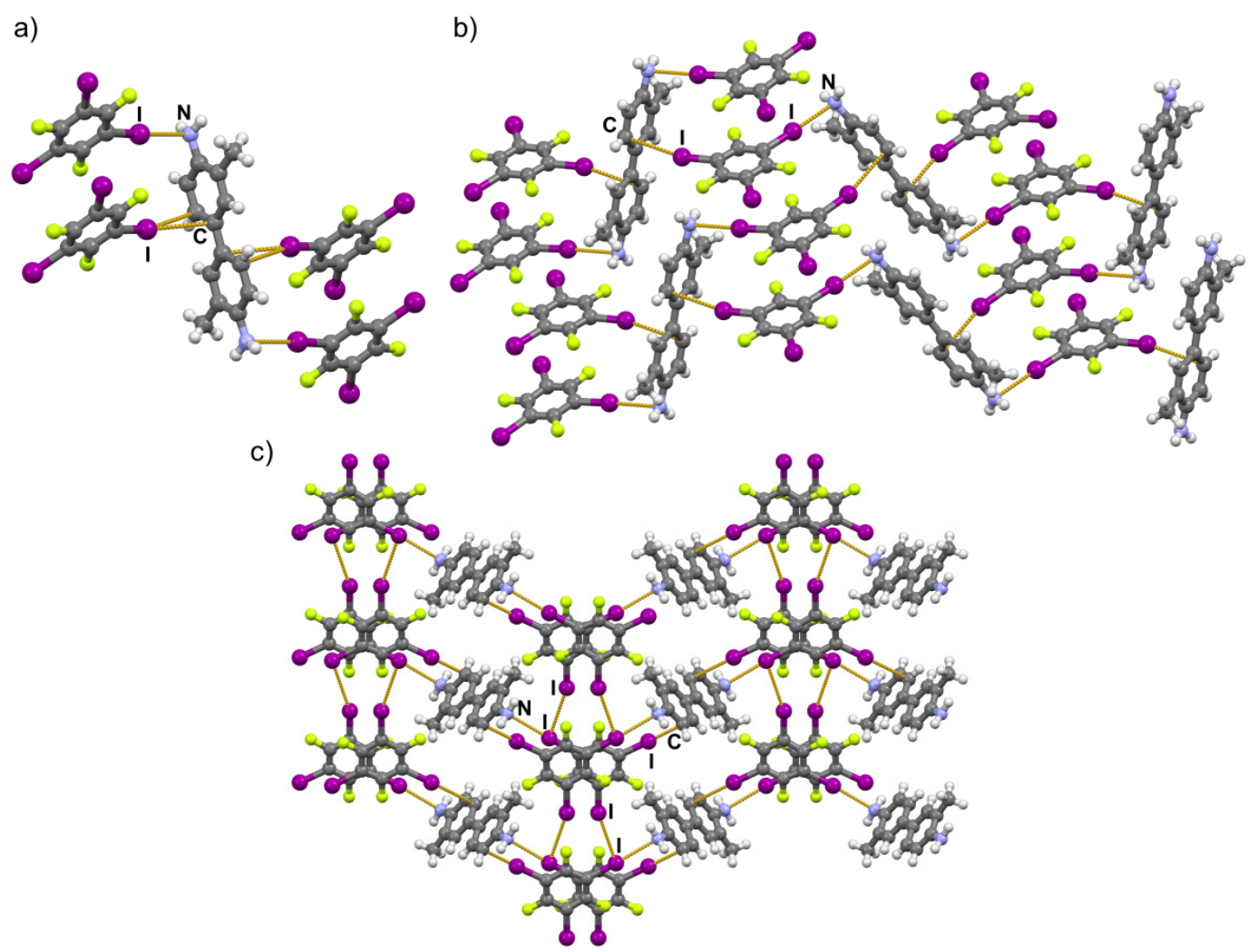

Figure 3. (a) Halogen bonding between otol and 135tfib molecules in the structure of (otol)(135tfib) 2 ; (b) a layer formed by linking otol and 135tfib molecules via $\mathrm{I} \cdots \mathrm{NH}_{2}$ and $\mathrm{I} \cdots \mathrm{C}_{\pi}$ halogen bonds in the structure of (otol)(14tfib); (c) layers connected through type II I -.I contacts into a 3D structure.

The last diamine, bnzd, yielded cocrystals with 13tfib and 135tfib, exhibiting stoichiometry 1:2 and 1:4, respectively. In the structure of the (bnzd)(13tfib) ${ }_{2}$ cocrystal, the arrangement of the donor and acceptor molecules is very similar to that in the (otol)(135tfib) $)_{2}$ cocrystal, with 13tfib molecule binding between two bnzd molecules (forming a halogen bond with the amino group of one and the aromatic $\pi$-system of the other $(d(\mathrm{I} 1 \cdots \mathrm{N} 1)=$ $\left.3.014(5) \AA, \angle(\mathrm{C} 7-\mathrm{I} 1 \cdots \mathrm{N} 1)=175.4(2)^{\circ} ; d(\mathrm{I} 2 \cdots \mathrm{C} 3)=3.518(6) \AA, \angle(\mathrm{C} 9-\mathrm{I} 2 \cdots \mathrm{C} 3)=156.8(2)^{\circ}\right)$, and each bnzd molecule binding overall four molecules of 13tfib, forming a $2 \mathrm{D}$ network of 8-molecular rings (Figure 4a). In the absence of the third iodine atom on the donor molecule, the halogen-bonded layers are interconnected into a 3D structure dominantly through $\mathrm{N}-\mathrm{H} \cdots \mathrm{F}$ hydrogen bonding contacts $(d(\mathrm{~N} 1 \cdots \mathrm{F} 2)=3.370(7) \AA$ ) (Figure $4 \mathrm{~b})$. 
a)

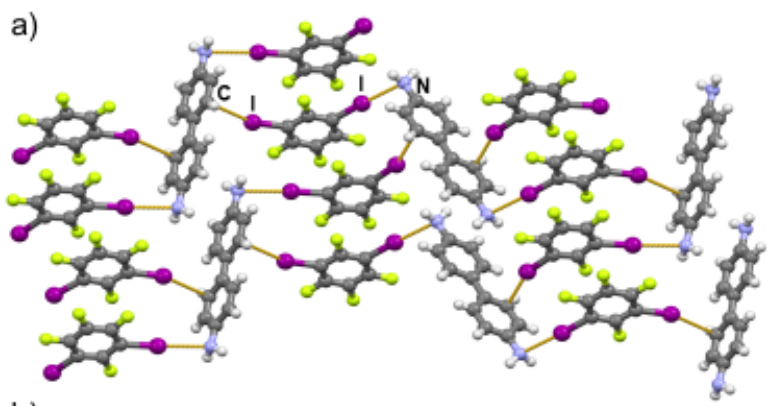

b)

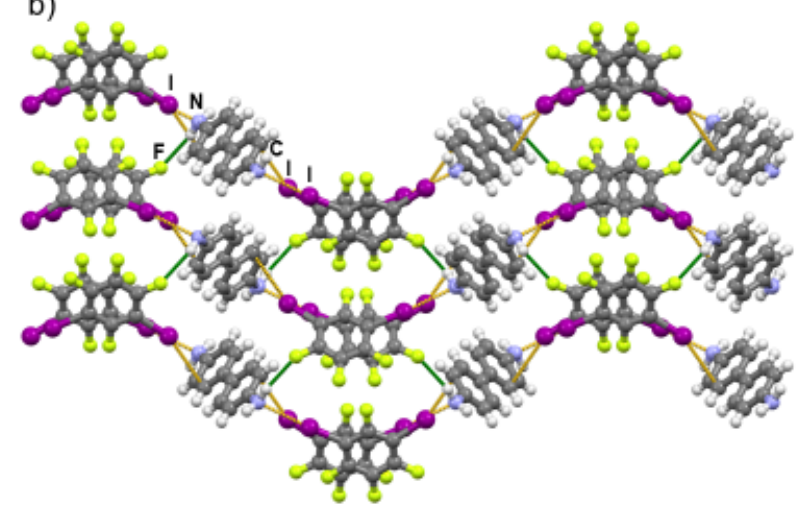

Figure 4. (a) Layers formed by linking bnzd and 13tfib molecules via $\mathrm{I} \cdots \mathrm{NH}_{2}$ and $\mathrm{I} \cdots \mathrm{C}_{\pi}$ halogen bonds (yellow) in the structure of (otol)(14tfib); (b) layers connected through $\mathrm{N}-\mathrm{H} \cdots$ F hydrogen bonds (green) into a 3D structure.

Interestingly, although bnzd does form a cocrystal with the tritopic 135tfib, its structure and stoichiometry are markedly different from both (bnzd)(13tfib $)_{2}$ and (otol)(135tfib) 2 cocrystals. The (bnzd)(135tfib) 4 cocrystal was found to be of 1:4 stoichiometry with four (a pair of two crystallographically independent) molecules of 135tfib bound to a single bnzd molecule, again two binding to the amino groups $(d(\mathrm{I} 1 \cdots \mathrm{N} 1)=3.05(1) \AA, \angle(\mathrm{C} 7-\mathrm{I} 1 \cdots \mathrm{N} 1)$ $\left.=175.8(4)^{\circ}\right)$ and two to the aromatic rings $(d(\mathrm{I} 5 \cdots \mathrm{C} 4)=3.48(1) \AA, \angle(\mathrm{C} 15-\mathrm{I} 5 \cdots \mathrm{C} 4)=$ $\left.157.3(3)^{\circ}\right)$ (Figure 5a). Here, however, they do not bridge between the diamine molecules, but rather participate in an array of type II iodine $\cdots$ iodine contacts $(d(\mathrm{I} 2 \cdots \mathrm{I} 1)=3.983(1)$ $\AA, \angle(C 9-I 2 \cdots$ I1 $\left.)=168.1(3)^{\circ} ; d(\mathrm{I} 4 \cdots \mathrm{I} 1)=3.878(2) \AA, \angle(\mathrm{C} 13-\mathrm{I} 4 \cdots \mathrm{I} 1)=174.9(3)^{\circ}\right)$ with neighbouring 135tfib molecules leading to highly corrugated layers (Figure $5 \mathrm{~b}$ ). These layers are again interconnected into a 3D structure via long $\mathrm{N}-\mathrm{H} \cdot \mathrm{F}$. hydrogen-bonding contacts $(d(\mathrm{~N} 1 \cdots \mathrm{F} 6)=3.17(2) \AA)$.

As can be seen from the above structure descriptions, in all of the five obtained cocrystals, the $\mathrm{N}-\mathrm{H} \cdots \mathrm{N}$ hydrogen bond (which is the dominant interaction in the crystal structures of the amines) is entirely replaced by $\mathrm{I} \cdots \mathrm{N}$ halogen bonds in the cocrystals, with amine hydrogen atoms participating mostly only in rather ephemeral $\mathrm{N}-\mathrm{H} \cdots$ F contacts. In order to investigate whether this coincides with a corresponding difference in the $\mathrm{R}$ $\mathrm{N}(\mathrm{H})-\mathrm{H} \cdots \mathrm{NH}_{2}$ hydrogen bond and the $\mathrm{C}-\mathrm{I} \cdots \mathrm{NH}_{2}$ halogen bond energies, we attempted to calculate the binding energies of chosen amine molecules in hydrogen-bonded dimers and halogen-bonded complexes with iodopentafluorobenzene (ipfb), and thus determined the relative strength of these interactions in vacuo. To avoid the presence of other acceptor sites in the molecules, we chose simple primary amines: aniline $\left(\mathrm{PhNH}_{2}\right)$ and methylamine $\left(\mathrm{MeNH}_{2}\right)$. From the results (Table 2), it can be noticed that the obtained binding energy for the aniline acceptor in hydrogen-bonded dimers is slightly higher $\left(0.8 \mathrm{~kJ} \mathrm{~mol}^{-1}\right)$ than for the complex with ipfb, indicating marginally larger stabilization of the hydrogenbonded complexes. However, the optimised structure of the hydrogen-bonded $\left(\mathrm{PhNH}_{2}\right)_{2}$ complex reveals the presence of a C-H $\cdots \pi$ contact (approximately the orthogonal position of the two aromatic rings), which almost certainly further stabilizes the aniline dimer (Figure 6a) [70]. In the optimized structure of $\left(\mathrm{PhNH}_{2}\right)(\mathbf{i p f b})$, such additional interactions 
are absent (Figure $6 \mathrm{~b}$ ), the only interaction between the molecules being a single I $\cdots \mathrm{N}$ halogen bond almost perpendicular $\left(\angle(\mathrm{I} \cdots \mathrm{N}-\mathrm{C})=106.6^{\circ}\right)$ to the plane of the aniline ring (which closely corresponds to the conformation of halogen-bonded complexes also observed in the cocrystal structures). Therefore, the calculated difference in binding energies for $\left(\mathrm{PhNH}_{2}\right)_{2}$ and $\left(\mathrm{PhNH}_{2}\right)(\mathbf{i p f b})$ does not pose a reliable representation of the difference in hydrogen- and halogen-bond energies with the primary amine as an acceptor (and donor of the former). In order to avoid the additional stabilisation of the hydrogenbonded complex by a C-H $\cdots \pi$ interaction, we opted for an additional set of computations using methylamine as the model primary amine molecule. In the $\left(\mathrm{MeNH}_{2}\right)_{2}$ dimer, the (H)NH $\cdots \mathrm{NH}_{2}$ hydrogen bond is indeed the only contact within the dimer (Figure 6c). Significantly, here the binding energy in the halogen-bonded (ipfb) $\left(\mathrm{MeNH}_{2}\right)$ complex (Figure $6 \mathrm{~d}$ ) is ca. $15 \mathrm{~kJ} \mathrm{~mol}^{-1}$ higher than the one for the hydrogen-bonded $\left(\mathrm{MeNH}_{2}\right)_{2}$ dimer. There is a difference in the basicities of the aliphatic and the aromatic primary amine groups - the aromatic amines being weaker bases-which makes the halogen bond in the (ipfb) $\left(\mathrm{MeNH}_{2}\right)$ complex stronger by ca. $8.4 \mathrm{~kJ} \mathrm{~mol}^{-1}$ than the corresponding bond in the $\left(\mathrm{PhNH}_{2}\right)(\mathbf{i p f b})$ complex. As this reduction in the basicity of the acceptor should also proportionally influence the hydrogen bond energy, it can therefore be expected that the contribution of the $\mathrm{R}-\mathrm{N}(\mathrm{H})-\mathrm{H} \cdots \mathrm{NH}_{2}$ hydrogen bond to the overall binding energy of the $\left(\mathrm{PhNH}_{2}\right)_{2}$ dimer is ca. $10 \mathrm{~kJ} \mathrm{~mol}^{-1}$ less than the overall energy itself, the rest being due to the $\mathrm{C}-\mathrm{H} \cdots \pi$ bond. Therefore, the computational results do indicate that the halogen bond between the primary amine group and a perfluorinated iodobenzene as a halogen bond donor is indeed more favourable than the $(\mathrm{H}) \mathrm{NH} \cdots \mathrm{NH}_{2}$ hydrogen bond between the amine groups, even in the case of aromatic amines, which is in line with the observed total absence of the said hydrogen bonds in the obtained cocrystals. However, they also indicate that weak interactions (e.g., C-H $\cdots \pi$ contacts) can have a sufficient contribution to the overall energy to alter this preference, which might explain our failure to prepare cocrystals of pphda with 13tfib and 135tfib; bnzd with 14tfib; and otol with 13tfib.

a)

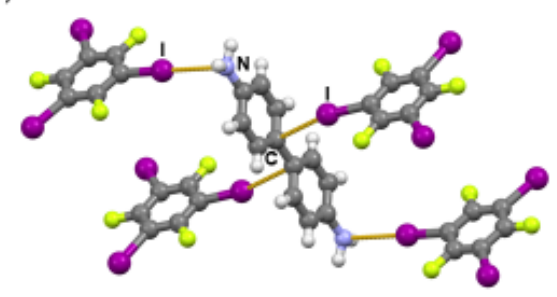

b)

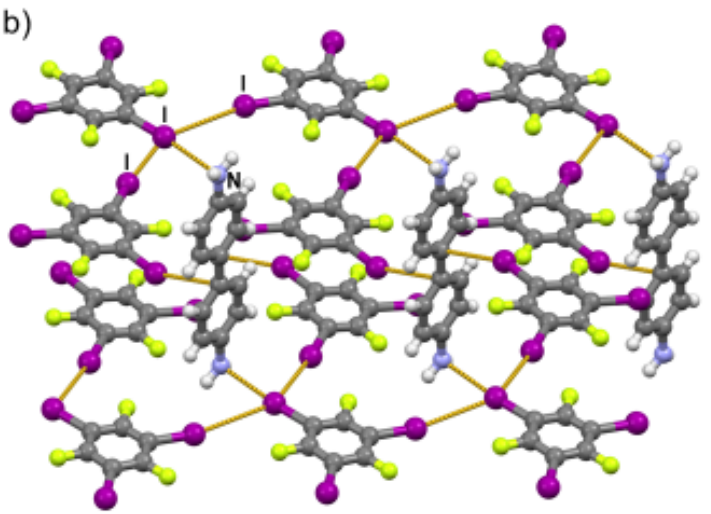

Figure 5. (a) Halogen bonding between bnzd and 135tfib molecules in the structure of (bnzd)(135tfib) ${ }_{4}$; (b) a layer formed by linking bnzd and 135 tfib molecules via $\mathrm{I} \cdots \mathrm{NH}_{2}, \mathrm{I} \cdots \mathrm{C}_{\pi}$ and I..I halogen bonds in the structure of $($ bnzd $)(\mathbf{1 3 5 t f i b})_{4}$. 
Table 2. Binding energies of (amine) $)_{2}$ dimers and (amine)(ipfb) complexes in vacuo.

\begin{tabular}{cc}
\hline Complex & E/kJ mol $\mathbf{~} \mathbf{~ 1 ~}^{-1}$ \\
\hline$\left(\mathrm{PhNH}_{2}\right)_{2}$ & -28.4 \\
$\left(\mathrm{PhNH}_{2}\right)(\mathbf{i p f b})$ & -27.6 \\
$\left(\mathrm{MeNH}_{2}\right)_{2}$ & -20.9 \\
$\left(\mathrm{MeNH}_{2}\right)(\mathbf{i p f b})$ & -36.0 \\
\hline
\end{tabular}

a)

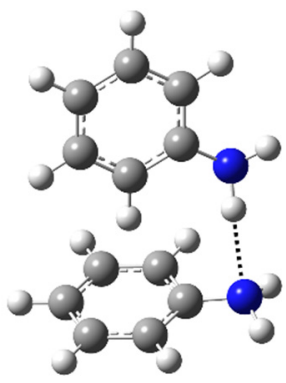

c)

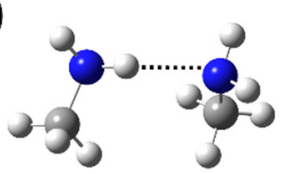

b)

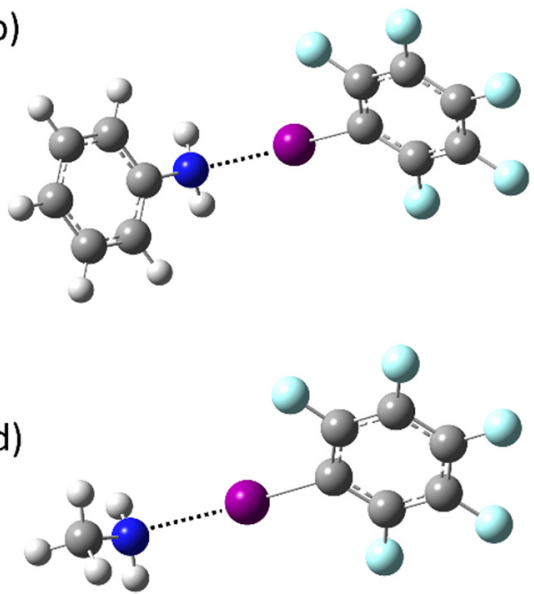

Figure 6. Optimized structures of (a) $\left(\mathrm{PhNH}_{2}\right)_{2} ;$ (b) $\left(\mathrm{PhNH}_{2}\right)(\mathrm{ipfb}) ; \quad$ (c) $\left(\mathrm{MeNH}_{2}\right)_{2}$; (d) $\left(\mathrm{MeNH}_{2}\right)(\mathbf{i p f b})$.

\section{Conclusions}

In the absence of competing halogen acceptors, the amine group has proven to be a reliable halogen bond acceptor, forming I $\cdots \mathrm{N}$ halogen bonds up to the total exclusion of $\mathrm{N}-\mathrm{H} \cdots \mathrm{N}$ hydrogen bonds, leaving the amine hydrogen atoms participating only in weakly bonding contacts. This is in line with the difference in the corresponding calculated bond energies with methylamine as the halogen/hydrogen bond acceptor. However, as only in 5 out of the 9 tested donor/acceptor combinations yielded cocrystals, it seems that this difference in halogen- and hydrogen-bond energies is not always sufficient to lead to the formation of a cocrystal. It is therefore probable that the deciding factors as to whether or not a halogen-bonded cocrystal of a primary (di)amine will be obtainable, will in many cases be from other contributions, such as the overall crystal packing of the reactants and the products.

Supplementary Materials: The following are available online at https:/ /www.mdpi.com/article/ 10.3390/cryst11050529/s1. Figure S1. Molecular structure of (pphda)(14tfib) showing the atomlabelling scheme. Displacement ellipsoids are drawn at the $50 \%$ probability level, and $\mathrm{H}$ atoms are shown as small spheres of arbitrary radius; Figure S2. Molecular structure of (bnzd)(13tfib) showing the atom-labelling scheme. Displacement ellipsoids are drawn at the $50 \%$ probability level, and $\mathrm{H}$ atoms are shown as small spheres of arbitrary radius; Figure S3. Molecular structure of (bnzd)(135tfib) $)_{4}$ showing the atom-labelling scheme. Displacement ellipsoids are drawn at the 50\% probability level, and $\mathrm{H}$ atoms are shown as small spheres of arbitrary radius; Figure S4. Molecular structure of (otol)(14tfib) showing the atom-labelling scheme. Displacement ellipsoids are drawn at the $50 \%$ probability level, and $\mathrm{H}$ atoms are shown as small spheres of arbitrary radius; Figure S5. Molecular structure of (otol)(135tfib) $)_{2}$ showing the atom-labelling scheme. Displacement ellipsoids are drawn at the $50 \%$ probability level, and $\mathrm{H}$ atoms are shown as small spheres of arbitrary radius; Figure S6. Measured (black) and calculated (blue) PXRD patterns of (pphda)(14tfib); Figure S7. Measured (black) and calculated (blue) PXRD patterns of (bnzd)(13tfib) 2 ; Figure S8. Measured (black) and calculated (blue) PXRD patterns of (bnzd)(135tfib) 4 ; Figure S9. Measured (black) and calculated (blue) PXRD patterns of (otol)(14tfib); Figure S10. Measured (black) and calculated (blue) 
PXRD patterns of (otol)(135tfib) ${ }_{2}$; Figure S11. DSC thermogram of product of solution synthesis of (pphda)(14tfib); Figure S12. DSC thermogram of product of solution synthesis of (bnzd)(13tfib)2; Figure S13. DSC thermogram of product of solution synthesis of $(\mathbf{b n z d})(\mathbf{1 3 5 t f i b})_{4}$; Figure S14. DSC thermogram of product of solution synthesis of (otol)(14tfib); Figure S15. DSC thermogram of (otol)(135tfib) $)_{2}$; Table S1. Masses of reactants and volumes of solvents for successful crystallization experiments; Table S2. An overview and crystallographic data of the prepared compounds; Total electron energies and Cartesian coordinates for optimised structures; An overview and crystallographic data of the prepared compounds. CCDC 2077218-2077222 contain crystallographic data for this paper. These data can be obtained free of charge from the Director, CCDC, 12 Union Road, Cambridge, CBZ 1EZ, UK (Fax: +44-12-2333-6033; email: deposit@ccdc.cam.ac.uk or http:/ /www.ccdc.cam.ac.uk).

Author Contributions: Conceptualization, V.S. and D.C.; methodology, V.S. and L.F.; cocrystal synthesis, E.U.; crystallization experiments, E.U.; characterization and X-ray diffraction analysis, L.F. and V.S.; calculations, N.B.; writing—original draft preparation, L.F. and V.S.; writing-L.F., V.S., N.B., E.U. and D.C.; supervision, V.S. and L.F.; project administration, D.C.; funding acquisition, D.C. All authors have read and agreed to the published version of the manuscript.

Funding: This research was supported by the Croatian Science Foundation under projects HRZZ-IP2014-09-7367 and HRZZ-IP-2019-04-1868.

Conflicts of Interest: The authors declare no conflict of interest. The funders had no role in the design of the study; in the collection, analysis or interpretation of data; in the writing of the manuscript; or in the decision to publish the results.

\section{References}

1. Legon, A.C. $\pi$-Electron "Donor-Acceptor" Complexes B ‥ClF and the Existence of the "Chlorine Bond". Chem. Eur. J. 1998, 4, 1890-1897. [CrossRef]

2. Legon, A.C. Prereactive Complexes of Dihalogens XY with Lewis Bases B in the Gas Phase: A Systematic Case for the Halogen

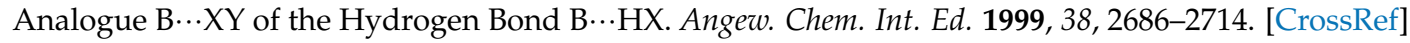

3. Corradi, E.; Meille, S.V.; Messina, M.T.; Metrangolo, P.; Resnati, G. Perfluorocarbon-hydrocarbon self-assembly. Part 6: $\alpha$, $\omega$-Diiodoperfluoroalkanes as pseudohalogens in supramolecular synthesis. Tetrahedron Lett. 1999, 40, 7519-7523. [CrossRef]

4. Amico, V.; Meille, S.V.; Corradi, E.; Messina, M.T.; Resnati, G. Perfluorocarbon-Hydrocarbon Self-Assembling. 1D Infinite Chain Formation Driven by Nitrogen $\cdots$ Iodine Interactions. J. Am. Chem. Soc. 1998, 120, 8261-8262. [CrossRef]

5. Metrangolo, P.; Resnati, G. Halogen Bonding: A Paradigm in Supramolecular Chemistry. Chem. Eur. J. 2001, 7, 2511-2519. [CrossRef]

6. Erdélyi, M. Halogen bonding in solution. Chem. Soc. Rev. 2012, 41, 3547-3557. [CrossRef]

7. Gilday, L.C.; Robinson, S.W.; Barendt, T.A.; Langton, M.J.; Mullaney, B.R.; Beer, P.D. Halogen Bonding in Supramolecular Chemistry. Chem. Rev. 2015, 115, 7118-7195. [CrossRef]

8. Pancholi, J.; Beer, P.D. Halogen bonding motifs for anion recognition. Coord. Chem. Rev. 2020, 416, 213281. [CrossRef]

9. Resnati, G.; Penningtonb, W.T. The halogen bond: A new avenue in recognition and self-assembly. New J. Chem. 2018, 42, 10461-10462. [CrossRef]

10. Cavallo, G.; Metrangolo, P.; Milani, R.; Pilati, T.; Priimagi, A.; Resnati, G.; Terraneo, G. The Halogen Bond. Chem. Rev. 2016, 116, 2478-2601. [CrossRef] [PubMed]

11. Ding, X.; Tuikka, M.; Haukka, M. Halogen Bonding in Crystal Engineering. In Recent Advances in Crystallography; Benedict, J.B., Ed.; IntechOpen: London, UK, 2012. [CrossRef]

12. Mukherjee, A.; Tothadi, S.; Desiraju, G.R. Halogen Bonds in Crystal Engineering: Like Hydrogen Bonds yet Different. Acc. Chem. Res. 2014, 47, 2514-2524. [CrossRef]

13. Aakeröy, C.B.; Wijethunga, T.K.; Desper, J. Practical crystal engineering using halogen bonding: A hierarchy based on calculated molecular electrostatic potential surfaces. J. Mol. Struct. 2014, 1072, 20-27. [CrossRef]

14. Cinčić, D.; Friščić, T.; Jones, W. Structural Equivalence of $\mathrm{Br}$ and I Halogen Bonds: A Route to Isostructural Materials with Controllable Properties. Chem. Mater. 2008, 20, 6623-6626. [CrossRef]

15. Chen, S.; Yin, H.; Wu, J.-J.; Lin, H.; Wang, X.D. Organic halogen-bonded co-crystals for optoelectronic applications. Sci. China Mater. 2020, 63, 1613-1630. [CrossRef]

16. Teyssandier, J.; Mali, K.S.; De Feyter, S. Halogen Bonding in Two-Dimensional Crystal Engineering. ChemistryOpen 2020, 9 , 225-241. [CrossRef]

17. Brammer, L.; Espallargas, G.M.; Libri, S. Combining metals with halogen bonds. CrystEngComm 2008, 10, 1712-1727. [CrossRef]

18. Bertani, R.; Sgarbossa, P.; Venzo, A.; Lelj, F.; Amati, M.; Resnati, G.; Pilati, T.; Metrangolo, P.; Terraneo, G. Halogen bonding in metal-organic-supramolecular networks. Coord. Chem. Rev. 2010, 254, 677-695. [CrossRef]

19. Li, B.; Zang, S.Q.; Wang, L.Y.; Mak, T.C.W. Halogen bonding: A powerful, emerging tool for constructing high-dimensional metal-containing supramolecular networks. Coord. Chem. Rev. 2016, 308, 1-21. [CrossRef] 
20. Nemec, V.; Lisac, K.; Bedeković, N.; Fotović, L.; Stilinović, V.; Cinčić, D. Crystal engineering strategies towards halogen bonded metal-organic multi-component solids: Salts, cocrystals and salt cocrystals. CrystEngComm 2021. [CrossRef]

21. Jakupec, N.; Fotović, L.; Stilinović, V. The effect of halogen bonding on protonated hexacyanoferrate networks in hexacyanoferrates of halogenopyridines. CrystEngComm 2020, 22, 8142-8150. [CrossRef]

22. Fotović, L.; Stilinovic, V. Halogenide anions as halogen and hydrogen bond acceptors in iodopyridinium halogenides. CrystEngComm 2020, 22, 4039-4046. [CrossRef]

23. Derossi, S.; Brammer, L.; Hunter, C.A.; Ward, M.D. Halogen Bonded Supramolecular Assemblies of $\left[\mathrm{Ru}(\mathrm{bipy})(\mathrm{CN})_{4}\right]^{2-} \mathrm{Anions}$ and N-Methyl-Halopyridinium Cations in the Solid State and in Solution. Inorg. Chem. 2009, 48, 1666-1677. [CrossRef] [PubMed]

24. Ormond-Prout, J.E.; Smart, P.; Brammer, L. Cyanometallates as Halogen Bond Acceptors. Cryst. Growth Des. 2011, 12, 205-216. [CrossRef]

25. Espallargas, G.M.; Zordan, F.; Marín, L.A.; Adams, H.; Shankland, K.; Van De Streek, J.; Brammer, L. Rational Modification of the Hierarchy of Intermolecular Interactions in Molecular Crystal Structures by Using Tunable Halogen Bonds. Chem. Eur. J. 2009, 15, 7554-7568. [CrossRef]

26. Zordan, F.; Purver, S.L.; Adams, H.; Brammer, L. Halometallate and halide ions: Nucleophiles in competition for hydrogen bond and halogen bond formation in halopyridinium salts of mixed halide-halometallate anions. CrystEngComm 2005, 7, 350-354. [CrossRef]

27. Lisac, K.; Topić, F.; Arhangelskis, M.; Cepić, S.; Julien, P.A.; Nickels, C.W.; Morris, A.J.; Friščić, T.; Cinčić, D. Halogen-bonded cocrystallization with phosphorus, arsenic and antimony acceptors. Nat. Commun. 2019, 10, 61. [CrossRef]

28. Zbačnik, M.; Pajski, M.; Stilinović, V.; Vitković, M.; Cinčić, D. The halogen bonding proclivity of the ortho-methoxy-hydroxy group in cocrystals of $o$-vanillin imines and diiodotetrafluoro-benzenes. CrystEngComm 2017, 19, 5576-5582. [CrossRef]

29. Carletta, A.; Zbačnik, M.; Vitković, M.; Tumanov, N.; Stilinović, V.; Wouters, J.; Cinčić, D. Halogen-bonded cocrystals of Nsalicylidene Schiff bases and iodoperfluorinated benzenes: Hydroxyl oxygen as a halogen bond acceptor. CrystEngComm 2018, 20, 5332-5339. [CrossRef]

30. Nemec, V.; Fotović, L.; Vitasović, T.; Cinčić, D. Halogen bonding of the aldehyde oxygen atom in cocrystals of aromatic aldehydes and 1,4-diiodotetrafluorobenzene. CrystEngComm 2019, 21, 3251-3255. [CrossRef]

31. Stilinović, V.; Grgurić, T.; Piteša, T.; Nemec, V.; Cinčić, D. Bifurcated and Monocentric Halogen Bonds in Cocrystals of Metal(II) Acetylacetonates with $p$-Dihalotetrafluorobenzenes. Cryst. Growth Des. 2018, 19, 1245-1256. [CrossRef]

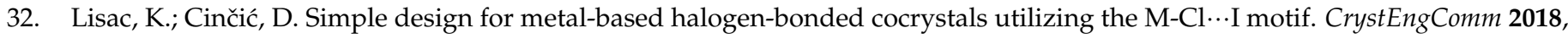
20, 5955-5963. [CrossRef]

33. Stilinović, V.; Horvat, G.; Hrenar, T.; Nemec, V.; Cinčić, D. Halogen and Hydrogen Bonding between (N-Halogeno)-succinimides and Pyridine Derivatives in Solution, the Solid State and In Silico. Chem. Eur. J. 2017, 23, 5244-5257. [CrossRef] [PubMed]

34. Troff, R.W.; Mäkelä, T.; Topić, F.; Valkonen, A.; Raatikainen, K.; Rissanen, K. Alternative motifs for halogen bonding. Eur. J. Org. Chem. 2013, 9, 1617-1637. [CrossRef]

35. Borley, W.; Watson, B.; Nizhnik, Y.P.; Zeller, M.; Rosokha, S.V. Complexes of Diiodine with Heteroaromatic N-Oxides: Effects of Halogen-Bond Acceptors in Halogen Bonding. J. Phys. Chem. A 2019, 123, 7113-7123. [CrossRef]

36. Topić, F.; Rissanen, K. Systematic Construction of Ternary Cocrystals by Orthogonal and Robust Hydrogen and Halogen Bonds. J. Am. Chem. Soc. 2016, 138, 6610-6616. [CrossRef] [PubMed]

37. Jay, J.I.; Padgett, C.W.; Walsh, R.D.B.; Hanks, A.T.W.; Pennington, W.T. Noncovalent Interactions in 2-Mercapto-1-methylimidazole Complexes with Organic Iodides. Cryst. Growth Des. 2001, 1, 501-507. [CrossRef]

38. Metrangolo, P.; Meyer, F.; Pilati, T.; Resnati, G.; Terraneo, G. 4,4'-Bipyridine-2,4,5,6-tetrafluoro-1,3-diiodobenzene. Acta Cryst. 2007, E63, o4243. [CrossRef]

39. Grebe, J.; Geiseler, G.; Harms, K.; Neumüller, B.; Dehnicke, K. Domino Effect in the Buildup of N-I-N-I Chains of the NIodine(triphenylphosphane)imine. Angew. Chem. Int. Ed. 1999, 38, 222-225. [CrossRef]

40. Lucassen, A.C.B.; Karton, A.; Leitus, G.; Shimon, L.J.W.; Martin, J.M.L.; Van Der Boom, M.E.; Martin, G. Co-Crystallization of Sym-Triiodo-Trifluorobenzene with Bipyridyl Donors: Consistent Formation of Two Instead of Anticipated Three N...I Halogen Bonds. Cryst. Growth Des. 2007, 7, 386-392. [CrossRef]

41. Bedeković, N.; Stilinović, V.; Friščić, T.D.; Cinčić, D. Comparison of isomeric meta- and para-diiodotetrafluorobenzene as halogen bond donors in crystal engineering. New J. Chem. 2018, 42, 10584-10591. [CrossRef]

42. Ding, X.H.; Chang, Y.Z.; Ou, C.J.; Lin, J.Y.; Xie, L.H.; Huang, W. Halogen bonding in the co-crystallization of potentially ditopic diiodotetrafluorobenzene: A powerful tool for constructing multicomponent supramolecular assemblies. Natl. Sci. Rev. 2020, 7, 1906-1932. [CrossRef]

43. Politzer, P.; Murray, J.S.; Clark, T. Halogen bonding: An electrostatically-driven highly directional noncovalent interaction. Phys. Chem. Chem. Phys. 2010, 12, 7748-7757. [CrossRef] [PubMed]

44. Legon, C. The halogen bond: An interim perspective. Phys. Chem. Chem. Phys. 2010, 12, 7736-7747. [CrossRef]

45. Gamekkanda, J.C.; Sinha, A.S.; Desper, J.; Đaković, M.; Aakeröy, C.B. Competition between hydrogen bonds and halogen bonds: A structural study. New J. Chem. 2018, 42, 10539-10547. [CrossRef]

46. Aakeröy, C.B.; Panikkattu, S.; Chopade, P.D.; Desper, J. Competing hydrogen-bond and halogen-bond donors in crystal engineering. CrystEngComm 2013, 15, 3125-3136. [CrossRef] 
47. Robertson, C.C.; Wright, J.S.; Carrington, E.J.; Perutz, R.N.; Hunter, C.A.; Brammer, L. Hydrogen bonding vs. halogen bonding: The solvent decides. Chem. Sci. 2017, 8, 5392-5398. [CrossRef]

48. Lombard, J.; Le Roex, T.; Haynes, D.A. Competition between Hydrogen and Halogen Bonds: The Effect of Solvent Volume. Cryst. Growth Des. 2020, 20, 7384-7391. [CrossRef]

49. Groom, C.R.; Bruno, I.J.; Lightfoot, M.P.; Ward, S.C. The Cambridge Structural Database. Acta Crystallogr. Sect. B Struct. Sci. Cryst. Eng. Mater. 2016, 72, 171-179. [CrossRef] [PubMed]

50. Nemec, V.; Cinčić, D. Uncommon halogen bond motifs in cocrystals of aromatic amines and 1,4-diiodotetrafluorobenzene. CrystEngComm 2016, 18, 7425-7429. [CrossRef]

51. Rafilovich, M.; Bernstein, J. Serendipity and Four Polymorphic Forms of Benzidine, $\mathrm{C}_{12} \mathrm{H}_{12} \mathrm{~N}_{2}$. J. Am. Chem. Soc. 2006, 128, 12185-12195. [CrossRef]

52. Czapik, A.; Konowalska, H.; Gdaniec, M. p-Phenylenediamine and its dihydrate: Two-dimensional isomorphism and mechanism of the dehydration process, and $\mathrm{N}-\mathrm{H} \cdots \mathrm{N}$ and $\mathrm{N}-\mathrm{H} \cdots \pi$ interactions. Acta Cryst. 2010, C66, 128-132. [CrossRef]

53. Chawdhury, S.A.; Hargreaves, A.; Sullivan, R.A.L. The crystal and molecular structure of 4,4'-diamino-3,3'-dimethylbiphenyl (o-tolidine). Acta Crystallogr. Sect. B Struct. Crystallogr. Cryst. Chem. 1968, 24, 1222-1228. [CrossRef]

54. Degen, T.; Sadki, M.; Bron, E.; König, U.; Nénert, G. The HighScore suite. Powder Diffr. 2014, 29, S13-S18. [CrossRef]

55. Crys Alis PRO CCD; Agilent Technologies Ltd.: Yarnton, UK, 2014.

56. Crys Alis PRO RED; Agilent Technologies Ltd.: Yarnton, UK, 2014.

57. Sheldrick, G.M. Crystal structure refinement with SHELXL. Acta Cryst. Sect. C Struct. Chem. 2015, 71, 3-8. [CrossRef]

58. Sheldrick, G.M. A short history of SHELX. Acta Cryst. A 2008, 64, 112-122. [CrossRef]

59. Sheldrick, G.M. SHELXT-Integrated space-group and crystal-structure determination. Acta Cryst. Sect. A Found. Adv. 2015, 71, 3-8. [CrossRef]

60. Farrugia, L.J. WinGX suite for small-molecule single-crystal crystallography. J. Appl. Cryst. 1999, 32, 837-838. [CrossRef]

61. Macrae, C.F.; Bruno, I.J.; Chisholm, J.A.; Edgington, P.R.; McCabe, P.; Pidcock, E.; Rodriguez-Monge, L.; Taylor, R.J.; Van De Streek, J.; Wood, P.A. Mercury CSD 2.0-New features for the visualization and investigation of crystal structures. J. Appl. Crystallogr. 2008, 41, 466-470. [CrossRef]

62. STARe Software, version 15.00; Mettler Toledo: Greifensee, Switzerland, 2016.

63. Frisch, M.J.; Trucks, G.W.; Schlegel, H.B.; Scuseria, G.E.; Robb, M.A.; Cheeseman, J.R.; Scalmani, G.; Barone, V.; Mennucci, B.; Petersson, G.A.; et al. Gaussian; Gaussian, Inc.: Wallingford, CT, USA, 2013.

64. Lee, C.; Yang, W.; Parr, R.G. Development of the Colle-Salvetti correlation-energy formula into a functional of the electron density. Phys. Rev. B 1988, 37, 785-789. [CrossRef]

65. Peverati, R.; Truhlar, D.G. An improved and broadly accurate local approximation to the exchange-correlation density functional: The MN12-L functional for electronic structure calculations in chemistry and physics. Phys. Chem. Chem. Phys. 2012, 14, 13171-13174. [CrossRef]

66. Feller, D. The role of databases in support of computational chemistry calculations. J. Comput. Chem. 1996, 17, 1571-1586. [CrossRef]

67. Grimme, S.; Antony, J.; Ehrlich, S.; Krieg, H. A consistent and accurate ab initio parametrization of density functional dispersion correction (DFT-D) for the 94 elements H-Pu. J. Chem. Phys. 2010, 132, 154104. [CrossRef]

68. Karpfen, A. Struct. Bonding (Berl.) 2008, 126, 1.

69. Rosokha, S.; Kochi, J. X-ray Structures and Electronic Spectra of the $\pi$-Halogen Complexes between Halogen Donors and Acceptors with $\pi$-Receptors. In Halogen Bonding. Fundamentals and Applications; Metrangolo, P., Resnati, G., Eds.; Springer: Berlin/Heidelberg, Germany, 2008; Volume 126, pp. 137-160.

70. Hunter, C.A.; Sanders, J.K.M. The nature of $\pi-\pi$ interactions. J. Am. Chem. Soc. 1990, 112, 5525-5534. [CrossRef] 